\title{
KHALIFAH/IMAM DALAM PERSPEKTIF TAFSIR SUNNI DAN SYIAH
}

\author{
Achmad Zubairin ${ }^{1}$ \\ alzuber82@gmail.com
}

\section{الخلاصة}

$$
\begin{aligned}
& \text { إن كمة الخليفة من القرون الأولى تضمن التفاسير العديدةية لا شكّ أنها أى اختلافات التفاسير العديدة }
\end{aligned}
$$

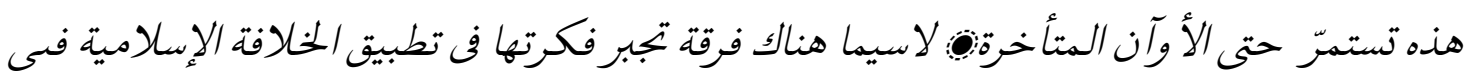

$$
\begin{aligned}
& \text { هذاالبلد. لكن الكاتب هنا سيبحث من الناحية التومينولجية فقطنة أمالناحية الإبستيمولوجية } \\
& \text { سيبحثها فى الفرصة القادمة. }
\end{aligned}
$$

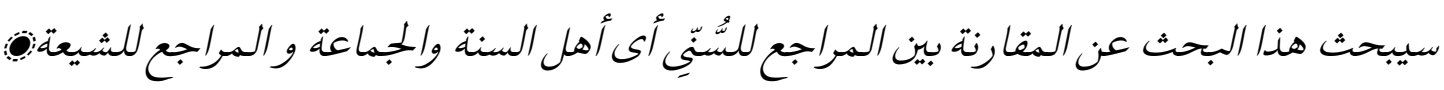

$$
\begin{aligned}
& \text { حيث أن لكل فرقة لها مميزات المختلفة في تفسيرها. من هذا الخلاف في أن التفسير لفرقةالشيعة يمتز }
\end{aligned}
$$

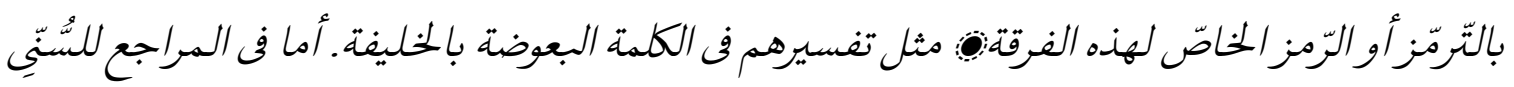

$$
\begin{aligned}
& \text { ليس هناك تفسيرا رمزيا كما يوجد فى فرقةالشيعة. }
\end{aligned}
$$

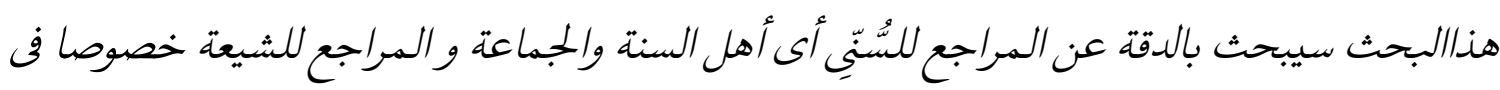

$$
\begin{aligned}
& \text { الكمة الخليفة أو الإمام. }
\end{aligned}
$$

\section{Sekilas Literatur Tentang Syiah}

Dalam literatur primer syi'ah klasik ada 4 kitab : (1) Al-Kafi (Al-Kulaini, 16099 riwayat), (2) Man La Yadhurruhul Faqih (Muhammad ibn Bawa`ih al-Qummi, 9044 riwayat) (3) Tahzibul Ahkam (Abu Ja'far Muhammad ibn Hasan al-thusi, w.360 h) (4) AlIstibshar ((Abu Ja'far Muhammad ibn Hasan al-thusi, w.360 h).

Sedangkan literatur primer syi'ah kontemporer juga ada 4 kitab yang dikenal dengan (al-majami' al-arba'ah al-muta 'akhirah) : (1) Al-Wafi (Muhammad ibn Murtadha, w 1091 H.) (2) Biharul Anwar al-Jami'ah li Durar Akhbar A`immatil Athar ( Muhammad

\footnotetext{
${ }^{1}$ Dosen Tetap Prodi Ilmu Al-Qur'an dan Tafsir STAI Asy-Syukriyyah
} 


\section{Jurnal Asy-Syukriyyah}

Baqir al-Majlisi, w.1110-1111 h.) (3) Wasa`ilu Syiah ila Tahsil Masa`il Syari'ah (Muh Hassan al-Hurr al-Amili) (4) Mustadrakul Wasa`il wa Mustambathul Masa il (Husain Nuri Thabrasi, w.1320 h). Namun penulis hanya membahas 1 buku literatur primer syi'ah klasik (Al-Kafi) dan 1 buku literatur sekunder syi'ah (Tafsir al-Qummi) saja, mengingat kedua buku ini menjadi pedoman dasar umat syi'ah.

\section{Tafsir Al-Qummi}

Ditulis oleh Abu al-Hasan Ali ibn Ibrahim ibn Hasyim al-Qummi, Termasuk perawi terkenal dikalangan ahlul bait, semasa dengan Imam Al-Askari, Imam Kulaini pun dalam menulis Al-Kafi banyak meriwayatkan darinya. Wafat tahun $307 \mathrm{~h}$.

Diantara karangan-karangannya : al-Nasikh wal Mansukh, Kitab Qurbul Isnad, Kitabul al-Syara i’, Kitabul Haidh, Kitabut Tauhid wa al-Syirk, Kitab Fadha`il Amiril Mu`minin, dll.

Diantara ulama yang ia riwayatkan antara lain : (1) Ibrahim ibn Hasyim (ayahnya sendiri) ia berasal dari Kufah lalu pindah ke Qumm, merupakan orang pertama yang menyebarkan Hadis di kota Qumm, ia juga bertemu dengan Ridha as. (2) Muhammad ibn Abi Amir ia hidup semasa dengan al-Kazim, al-Ridha, dan al-Jawad as. Pada masa Harun al-Rasyid ia dicambuk oleh al-Sanadi ibn Syahik namun akhirnya ia membayar uang jaminan. Sejarah juga mencatat bahwa pada masa kekhalifahan Al-Ma`mun, sang khalifah memenjarakannya selama 4 tahun yaitu setelah wafatnya al-Ridha as.

Manuskrip asli Tafsir Al-Qummi termasuk Tafsir yang jarang ditemukan mengingat dicetak hanya dua kali di Iran : tahun 1313 h. Dan 1315 h. Keistimewaan tafsir ini diantaranya : (1)Merupakan sumber primer dalam ilmu tafsir, (2)Riwayatnya berasal dari orang-orang yang jujur (shadiqin), (3)Pengarang sezaman dengan Imam al-Askari, (4)Ayah si pengarang adalah sahabat al-Ridha as.(5)Berisikan Keutamaan-keutamaan Ahlul Bait, (6)Pemahaman yang lebih jelas dengan penjelasan ulama Ahlul Bait.

Yang mentahqiq tafsir ini : Syeikh Aqa Bazrak al-Taherani Dam Zilluh al-Ali, dan al-Alamah al-Sayyid Thayib al-Musa al-Jaza`iri. Tafsir ini lebih tepat disebut Ta`wil.

عن ابي عبداله عليه السلام ان هذا المثل ضربه الله لامير المؤمنين عليه السلام فالبعوضة امير

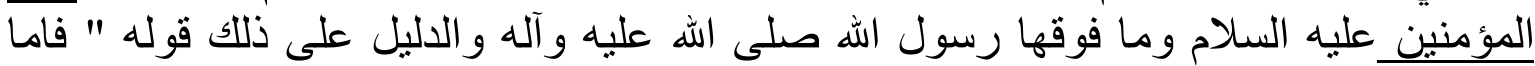
الذين آمنو ا فيعلمون انه الحق من ربهم " يعنى امير المؤمنين كما اخذ رسول الله صلى الله عليه 


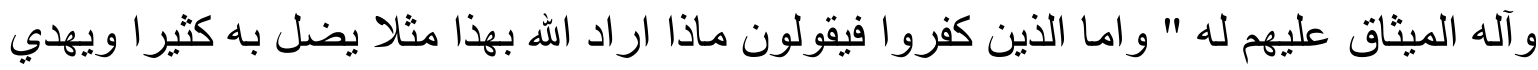

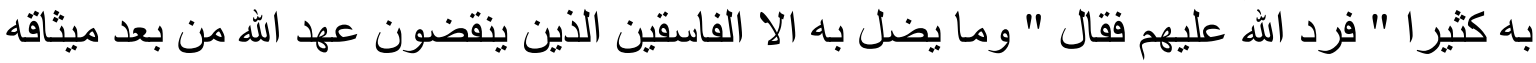

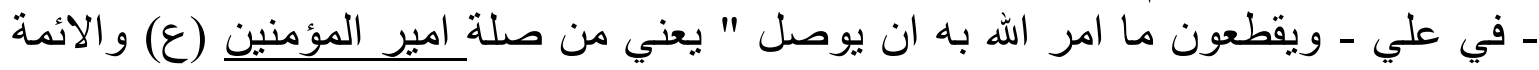

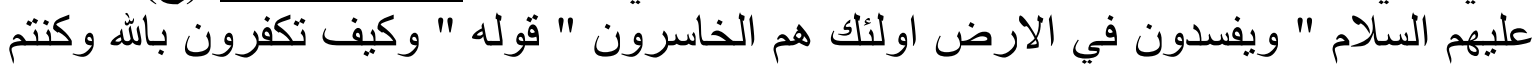

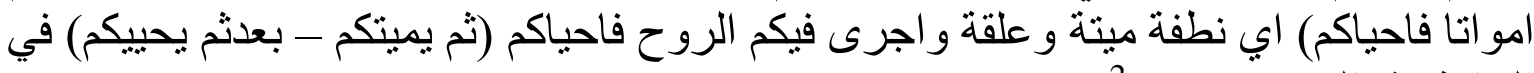

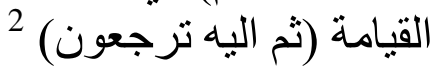

1. Maksud ayat "Sesungguhnya Allah tidak malu menciptakan nyamuk", Menurut alShadiq as. ayat ini sebagai bantahan terhadap anggapan bahwa Allah menyesatkan makhluk-Nya yang menyebabkan mereka mendapat azab. Ayat ini juga ditafsirkan : Ayahku menceritakan kepadaku, dari Nadhir bin Sawid, dari Qasam bin Sulaiman, dari al-Mu'alla bin Khanis dari Abu Abdullah as. sesungguhnya ayat ini menggambarkan Amirul Mu`minin, maka "baudhah” maksudnya adalah Amirul Mu minin, sedangkan "wama fauqaha” ialah Rasulullah Saw. Dalilnya adalah "Sedangkan orang-orang yang beriman mereka mengetahui bahwasannya itu adalah benar", maksudnya adalah Amirul Mu’minin dimana Nabi Saw juga mengakuinya, "Mereka meninggalkan perintah Allah untuk menyambung", juga ditujukan kepada Amirul Mu`minin. (Q.s. Al-Baqarah : 30)

و هو الذي جعلكم خلائف الارض ورفع بعضكم فوق بعض درجات) قال في القدر و المال

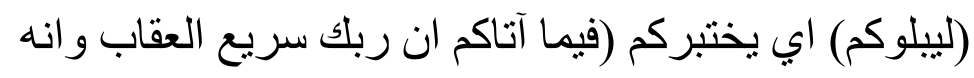

2. "Dan Dialah yang menjadikan kamu penguasa-penguasa di bumi dan Dia meninggikan sebahagian kamu atas sebahagian (yang lain) beberapa derajat." Yaitu dalam hal kemampuan dan harta. (Q.s. Al-An'am : 165)

ثم جعلناكم خلائف في الارض من بعدهم لننظر كيف تعملون) بعني حتى نرى فوض الرؤية

3. "Kemudian Kami jadikan kamu pengganti-pengganti (mereka) di muka bumi sesudah mereka, supaya Kami memperhatikan bagaimana kamu berbuat. Maksudnya supaya Kami melihatnya. (Q.s. Yunus : 14)

\footnotetext{
${ }^{2}$ Abu Hasan Ali Ibrahim Al-Qummi, Tafsir Al-Qummi, Darul Kutub, Qumm-Iran, hal.55-56.
} 
(و إذ ابتلى ابر اهيم ربه بكلمات فاتمهن قال إني جاعلك للناس اماما) قال هو ما ابتلاه الله وفي تفسير الامام العسكري عليه السلام مرويا عن الصادق عليه السلام ان المراد من تلك الكلمات، الكلمات التي تلقاها آدم عليه السلام من ربه فتاب عليه وهي انه قال " يارب اسألك بحق محمد و علي وفاطمة والحسن والحسين الا تبت علي " ـ قيل له يابن رسول الله فما بعني بقوله " فاتمهن "؟ قال " بعني فاتمهن إلى القائم عليه السلام (الرواية)

4. "Dan (ingatlah) ketika Ibrahim diuji Tuhannya dengan beberapa kalimat (perintah dan larangan) lalu Ibrahim menunaikannya. Ibrahimlah orang yang diberi ujian. Dalam Tafsir Imam al-Askari diriwayatkan dari al-Shadiq as. maksud dari kalimat adalah kalimat yang diterima nabi Adam as dari Allah dimana ia dimaafkan, nabi Adam as. berdoa : Ya Allah aku berdoa demi Muhammad, Ali, Fatimah, Hasan dan Husain. Kabulkanlah doaku. Lalu apa maksud "menunaikannya" dijawab bahwa maksudnya adalah menunaikannya bagi al-Qa im as. (Q.s. Al-Baqarah : 124) (أمن يجيب المضطر إذا دعاه ويكثف السوء ويجعلكم خلفاء الارض) فانه حدثي ابي عن الحسن بن علي بن فضال عن صالح بن عقبة عن ابي عبداله عليه السلام قال: نزلت في القايم من آل محمد عليهم السلام، هو والله المضطر إذا صلى في المقام ركعتين ودعا الله فأجابه ويكثف السوء ويجعله خليفة في الارض وهذا مما ذكرنا ان تأويله بعد تنزيله

5. “Atau siapakah yang memperkenankan (doa) orang yang dalam kesulitan apabila ia berdoa kepada-Nya, dan yang menghilangkan kesusahan dan yang menjadikan kamu (manusia) sebagai khalifah di bumi. Ayahku menceritakan kepadaku dari Hasan bin Ali bin Fadhdhal dari Shalih bin Aqabah dari Abi Abdillah as : ayat ini turun pada al-Qa`im keturunan nabi Muhammad saw. Demi Allah dialah yang dimaksud yaitu yang shalat dua rakaat di surau kemudian berdoa dan Allah Swt pun mengabulkan permintaannya, menghilangkan kesukaran dan menjadikannya sebagai khalifah di atas muka bumi. (Q.s. al-Naml : 62)

قال: وقرئ عند ابي عبداله عليه السلام (والذين يقولون ربنا هب لنا من ازواجنا وذرياتتا قرة اعين واجعلنا للمتقين إماما) فقال قد سألوا الله عظيما ان يجعلهح للمتقين 


\section{Jurnal Asy-Syukriyyah}

أئمة ! فقيل له كيف هذا يا بن رسول الله قال انما انزل الله " الذين يقولون ربنا هب لنا من ازواجنا وذرياتنا قرة اعين واجعل لنا من المتقين إماما " حدثنا محمد بن احمد قال حدثنا الحسن بن محمد عن حماد عن ابان ابن تغلب قال سألت ابا عبدالله عليه السلام عن قول الله عزوجل " الذين يقولون ربنا هب لنا من ازواجنا وذرياتنا قرة اعين واجعلنا للمتقين إمامـا " قال نحن هم اهل البيت وروى غيره ان " ازو اجنا " خديجة " وذرياتنا " فاطمة " وقرة اعين " الحسن والحسين " واجعلنا للمتقين إماما " علي بن ابي طالب عليه السلام وفي رواية ابي الجارود عن ابي جعفر عليه السلام في قوله (قل ما يعبؤا

$$
\text { بكم ربي لو لا دعاؤكم) }
$$

6. Muhammad bin Ahmad menceritakan kepada kami, dari Hammad dari Abban bin Taghlab berkata : Aku bertanya kepada Abu Abdillah tentang firman Allah : "Dan orang-orang yang berkata...." ia berkata : Kami ahlul bait adalah mereka, dalam riwayat lain disebutkan : "Istri-istri kami" adalah Khadijah, "keturunan kami" adalah Fatimah, "penyenang hati (kami)" maksudnya Hasan dan Husain, "dan jadikanlah kami imam bagi orang-orang yang bertaqwa" maksudnya Ali ra. (Q.s.al-Furqan :74)

ونريد ان نمن على الذين استضعفو ا في الارض ونجعلهم أئمة ونجعلهم الوارثين ونمكن لهم في الارض ونري فرعون وهامان وجنودهما) وهم الذين غصبوا آل محمد حقهم

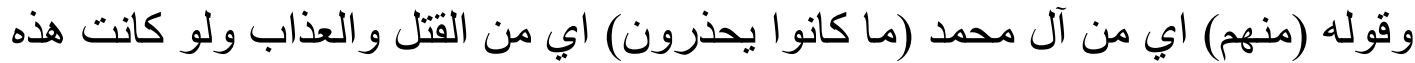
الآية نزلت في موسى وفرعون لقال ونري فرعون وهامان وجنودهما منه ما كانوا يحذرون اي من موسى ولم بقل منهم فلما تقدم قوله " ونريد ان نمن على الذين

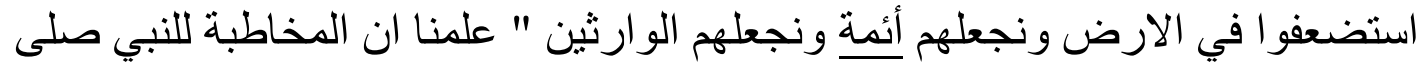
الله عليه و آله وما و عد الله به رسوله فانما يكون بعده والائمة يكونون من ولده و إنما ضرب الله هذا المثل لهم في موسى وبني اسرائيل وفي اعدائهح بفرعون وهامان وجنودهما فقال: إن فر عون قتل بني اسر ائيل وظلم من ظلمهم فأظفر الله موسى بفرعون و اصحابه حتى اهلكهم الله وكذلك اهل بيت رسول الله صلى الله عليه و آله اصابهم من لن بن اعدائهم القتل و الغصب ثم يردهم الله ويرد اعداءهم إلى الدنيا حتى يقتلو هم 


\section{Jurnal Asy-Syukriyyah}

7. Kami akan memberikan kepada orang-orang yang terzalimi di bumi kemudian Kami jadikan mereka Pemimpin dan merekalah yang berhak mewariskan dan Kami lestarikan mereka dan bahwasannya Fir'aun dan bala tentaranyalah yang telah merampas hak-hak dari keturunan Nabi Muhammad Saw. Kata "dari mereka", maksudnya dari keturunan Nabi Muhammad Saw. "Seharusnya mereka berhatihati" yaitu dari pembunuhan dan beragam siksaan, ayat ini walaupun turun pada Musa as. dan Fir'aun, namun ini didahului oleh ayat yang berbunyi, "Kami akan berikan...." maka sesungguhnya objek dalam ayat ini adalah Nabi Muhammad Saw. dan Para Pemimpin dari keturunannya. Perumpamaan pertolongan Allah Swt kepada Nabi Musa as. terhadap Bani Isra il adalah seperti Ahlul Bait Rasulullah Saw. dari pembunuhan dan siksaan musuh-musuhnya. (Q.s. al-Qashash :5)

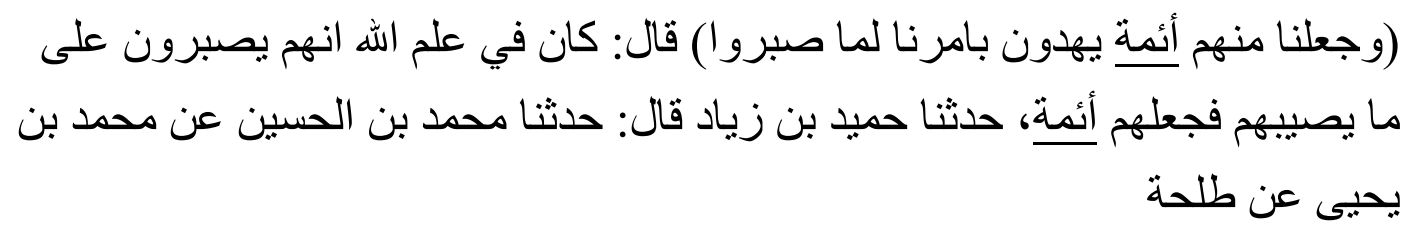

8. "Dan Kami jadikan diantara mereka itu pemimpin-pemimpin yang memberi petunjuk dengan perintah Kami ketika mereka sabar." Allah mengetahui kesabaran mereka sehingga mereka mendapat pertolongan. (Q.s. Al-Sajadah : 24)

سعيد عن حماد بن عيسى عن ربعي بن عبداله بن الفضيل بن يسار (سيار ط) عن ابى

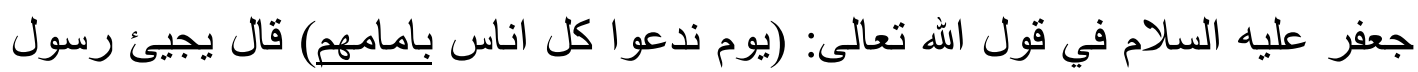
الله صلى الله عليه و آله في فرقة و على في فرقة والاحسن في فرقة و الحسين في فرقة

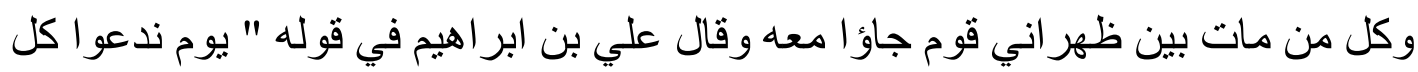

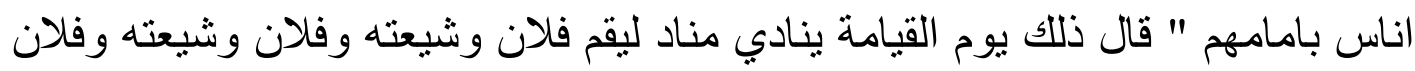
وشيعته و علي وشيعته

9. Dari Sa'id dari Hammad dari Isa dari Rib'i' bin Abdillah bin al-Fadhil bin Yasar dari Abi Ja'far as. tentang ayat “(ingatlah) suatu hari (yang dihari itu) Kami panggil tiap umat dengan pemimpinnya”, Rasulullah Saw datang beserta 
keluarganya, Ali dengan kelompoknya, Hasan dengan kelompoknya, Husain dengan kelompoknya, dan setiap yang wafat diantara kelompoknya akan datang dengan kelompoknya pada hari kiamat. Ali bin Ibrahim berkata tentang ayat ini juga : Pada hari kiamat nanti seseorang akan datang beserta kelompoknya, seorang lainnya akan datang beserta kelompoknya, seorang lainnya akan datang beserta kelompoknya, dan Ali beserta kaum Syi'ah. (Q.s. al-Isra` : 71)

\section{Kitab Ushul al-Kafi}

Pengarangnya Abu Ja'far Muhammad ibn Ya'qub ibn ibn Ishaq al-Kulaini alRazi, lahir di Kulain Ray Iran, ia pernah tinggal di Baghdad. Wafat th. 328-329 h (939-940 m.) dimakamkan di kufah. Hidup di masa dinasti Buwaihiyah (945-1055 m.)

Ia merupakan ulama ahli hadis generasi keempat setelah generasi pertama : AlThusi dan al-Najasyi, generasi kedua : Syeikh al-Mufid dan Ibn Al-Ghadari'i, generasi ketiga : al-Shaduq dan Ahmad bin Muhammad.

Dalam mengarang al-Kafi ia mengembara ke Irak, Damaskus, Ba'albak, Talfis selama 20 tahun. Diantara guru-gurunya Ahmad ibn Abdullah ibn Umayyah, Ishaq ibn Ya'qub al-Hasan ibn Khafif, Ahmad ibn Mihran, Muhammad ibn Yahya, Muhammad ibn Aqil. Murid-muridnya adalah Abu al-Husain Ahmad ibn Ali ibn Sa'id al-Kufi, Abu alQasim Ja'far ibn Muhammad ibn Muhammad ibn Sulaiman ibn Hasan ibn al-Jahm ibn Bakr, Muhammad ibn Muhammad ibn 'Ashi m al-Kulaini, Abu Muhammad Harun ibn Musa ibn Ahmad ibn Said ibn Said.

Kitab-kitab karangannya : Tafsir Ru`ya, Tafsir al-Rijal, al-Rad alal Qaramithah, Rasa`il A`immah Alaihi Salam, al-Kafi, Ma Qiila fil A`immah Alaihi Salam min al-Syiah, al-Dawajin wa al-Rawajin, al-Zayyu wa al-Tajammul, al-Wasa il, al-Raudhah.

Hadis-hadisnya menurut Al-Khunsari (16.190 hadis), Al-Majlisi (16.121), Agha Buzurg al-Tihrani (15.181), Ali Akbar Al-Ghifari (15.176). al-Kafi terdiri dari 8 jilid, 2 jilid berisi Ushul, 4 jilid lainnya masalah Furu'. Jilid I (1437 hadis), jilid II (2346), jilid III (2049), jilid IV (2443), jilid V (2200), jilid VI (2727), jilid VII (1704), jilid VIII (597). Jumlah keseluruhan adalah 15.503 hadis minus 618 hadis karena kesamaan sanad. 


\section{Jurnal Asy-Syukriyyah}

Hasil penelitian al-Alamah al-Hilli (w 598 h.) dan al-Majlisi dengan kaedah Ulumul Hadis adalah 5.027 Hadis Shahih, 144 Hadis Hasan, 1.128 Hadis Muwassaq, 302 Hadis Qawi, 9.485 Hadis Dha'if.

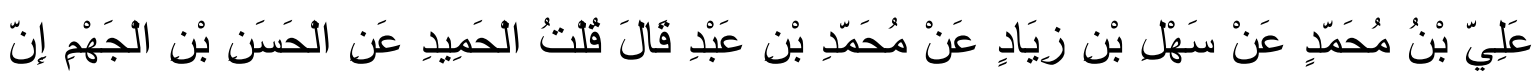

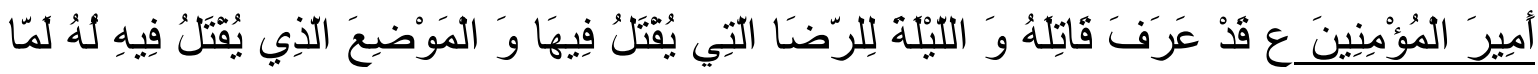

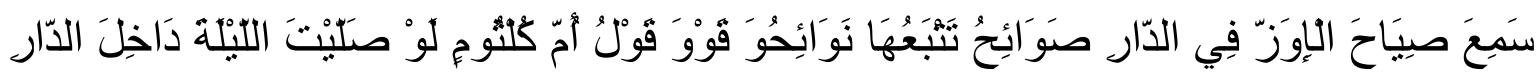

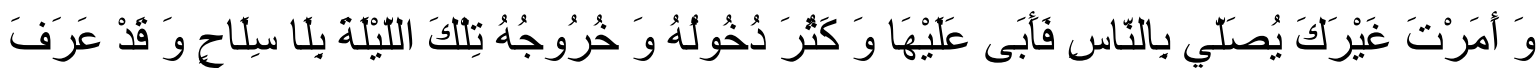

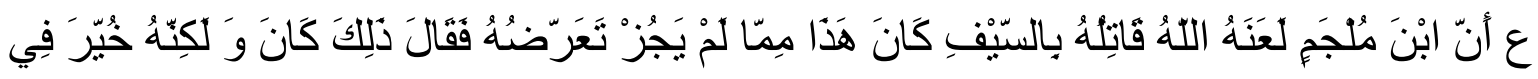

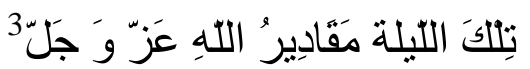

1- Dari Ali bin Muhammad dari Sahal bin Ziyad dari Muhammad bin Abdul Hamid dari Hasan bin Jahm berkata : Aku berkata kepada Ridha: Amirul Mu`minin telah mengetahui pembunuhnya dan di malam kematiannya pada tempat ia dibunuh dan ungkapannya ketika ia mendengar teriakan kegaduhan dari dalam rumahnya disertai dengan suasana di malam hari, dan engkau memerintahkan orang lain tapi ia menolak untuk shalat berjama'ah, dan permintaan Ummi Kultsum agar engkau shalat dirumah saja, ia juga sering keluar-masuk rumah tanpa pedang dan sesungguhnya ia mengetahui bahwa Ibnu Muljam akan membununya dengan pedang dan ia telah mengungkapkannya akan tetapi ini adalah pilihannya dan telah menjadi ketetapan Allah baginya. (Ushul Kafi I, bab : Imam Mengetahui Kematiannya dan Kematian Tidak Datang kecuali Atas Kehendak Mereka, hlm. 384, no. Riwayat. 4)

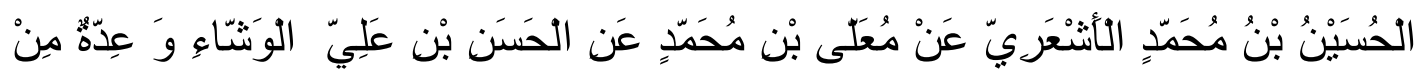

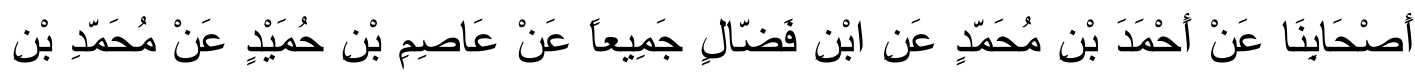

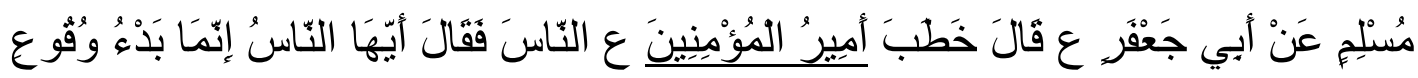

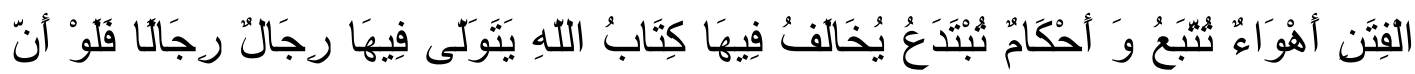

\footnotetext{
${ }^{3}$ Muhammad bin Ya'qub Al-Qulainiy, Ushul Kafi, Darul Murtadha Beirut. Hal.128-129.
} 


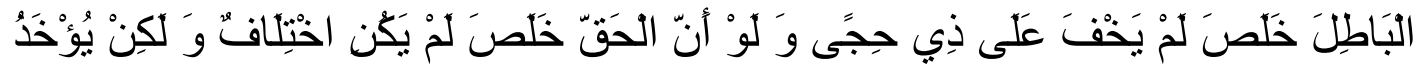

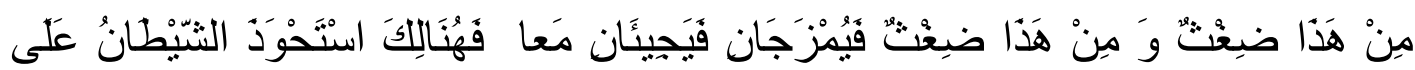

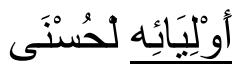

2- Dari Husain bin Muhammad Al-Asy'ari dari Ma'la bin Muhammad dari Hasan bin Wasysya' serta beberapa sahabat kami dari Ahmad bin Muhammad dari Ibnu Fadhdhal seluruhnya dari Ashim bin Humaid dari Muhammad bin Muslim dari Abu Ja'far, ia berkata : Amirul Mu'minin berkata: Celakalah manusia ! Wahai manusia Suatu fitnah ialah menuruti hawa nafsunya dan melakukan perkara bid'ah dan Al-Qur`an melarangnya, manusia menuhankan manusia, seandainya kebatilah yang tampak maka bersegeralah manusia mengikutinya, tapi jika kebenaran yang tampak manusia segera menolaknya kemudian darinya terjadilah perpecahan, dua hal ini kekacauan dan bercampurlah antara yang benar dan salah kemudian sampailah kepada para pemimpin yang baik. (Ushul Kafi I,hlm. 69, no. Riwayat. 1

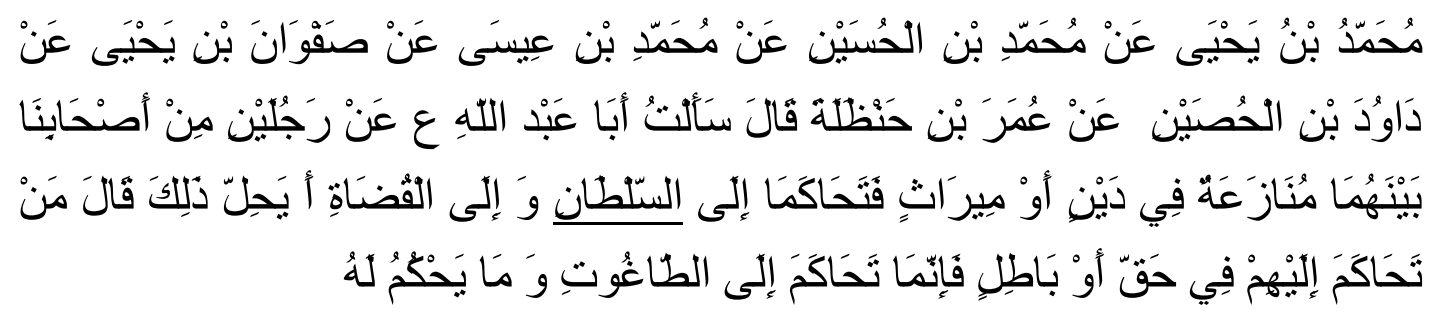

3- Dari Muhammad bin Muhammad bin Yahya dari al-Husain dari Muhammad bin Isa dari Shafwan bin Yahya dari Daud bin al-Husain dari Umar bin Hanzhalah, ia berkata : Aku bertanya kepada Abu Abdillah tentang dua orang laki-laki yang sedang bertentangan dalam hal agama dan warisan kemudian mengadu kepada raja dan atau kepada hakim apakah bisa diselesaikan ? ia kemudian berkata : Barangsiapa yang melaporkan kepada mereka perihal yang haq dan bathil maka sesungguhnya ia telah mengadukan kepada setan. (Ushul Kafi I, bab : Perbedaan tentang Hadist, hlm. 86, no. Riwayat. 10) 


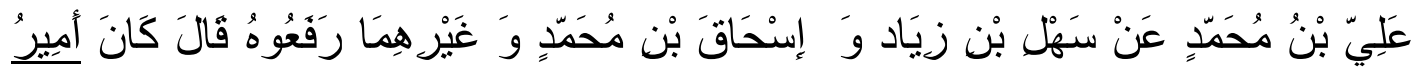

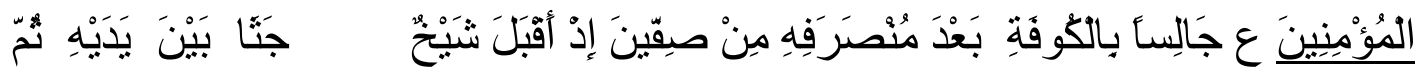

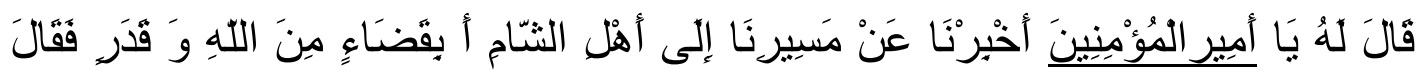

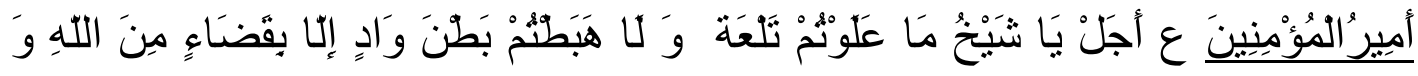

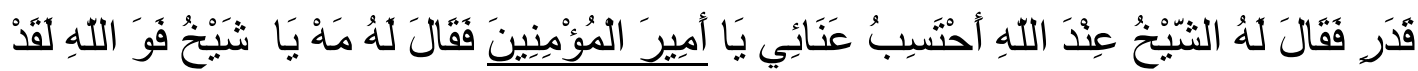

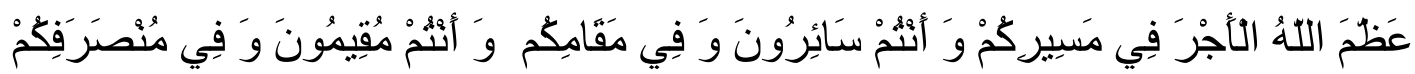

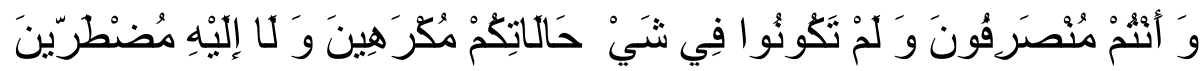

4- Dari Ali Bin Muhammad dari Sahal bin Ziyad Ishaq bin Muhammad dan selain keduanya membenarkan hadist ini, ia berkata : Suatu hari Amirul Mu minin sedang duduk di kota Kufah setelah kepulangannya dari perang Shiffin kemudian datanglah seorang kakek dan berkata : wahai Amirul Mu`minin beritakan kepada kami tentang perjalanan menuju Syam, apakah atas kehendak Allah atau kehendak manusia, Amirul Mu`minin berkata : Benar wahai kakek! Pegunungan yang kalian lalui adalah karena kehendak Allah dan kehendak kalian, sang kakek berkata: Aku mohon keridha-an dari Allah hai Amirul Mùminin. Ia menjawab : Benar wahai kakek, sesungguhnya perjalanan kalian telah diridhai Allah dan tempatilah oleh kalian tempat kalian saat ini dan tinggalkanlah dengan baik. Dan janganlah kalian membenci kehendak Allah dan merasa terpaksa. (Ushul Kafi I, Bab: Jabr dan Qadar dan Amr bainal Amraini, hlm. 215, no. Riwayat. 1)

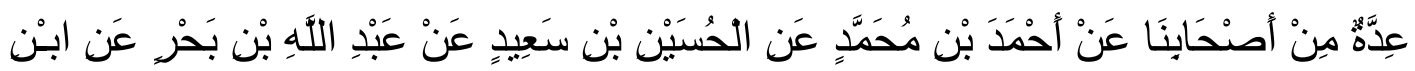

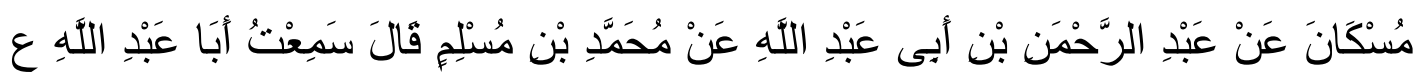

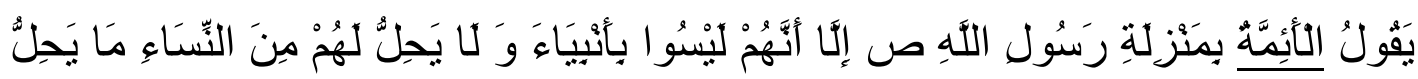

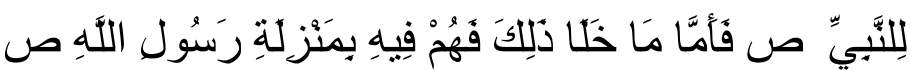

5- Dari beberapa sahabat kami, dari Ahmad bin Muhammad, dari Husain bin Sa'id, dari Abdullah bin Bahr dari Ibnu Muskan dari Abd bin Muslim, ia berkata : Aku mendengar Arrahman bin Abi Abdillah dari Muhammad dari kecuali Abu Abdillah ia berkata : Para Imam pengganti Rasulullah Saw dan mereka bukanlah para nabi, mereka tidak sama dengan nabi Saw dalam berpoligami, dan selain hal tersebut 


\section{Jurnal Asy-Syukriyyah}

mereka sama seperti Nabi Saw. (Ushul Kafi 2, bab : Para Imam Sama seperti Pendahulunya dan Dibencinya Menganggap Mereka Sebagai Nabi, hlm. 5, no. Riwayat. 3)

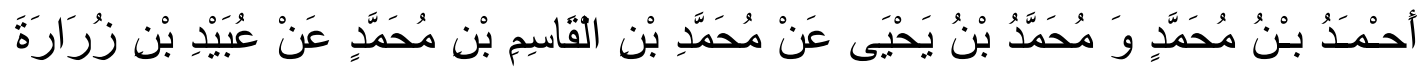

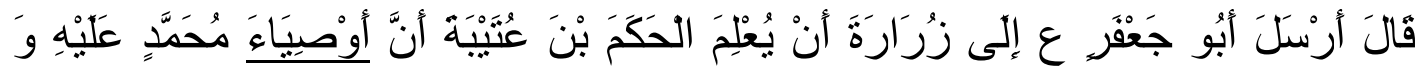

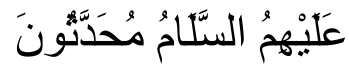

6- Dari Ahmad bin Muhammad dan Muhammad bin Yahya dari Muhammad bin Qasim bin Muhammad dari Ubaid bin Zurarah ia berkata : Abu Ja'far mengutus kepada Zurarah agar memberitahu kepada al-Hukm bin Utaibah bahwa Pewaris Nabi Muhammad diceritakan (Ushul Kafi 2, bab : Para Imam Diceritakan dan Difahamkan, hlm. 13, no. Riwayat. 1)

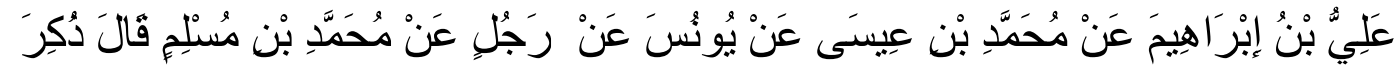

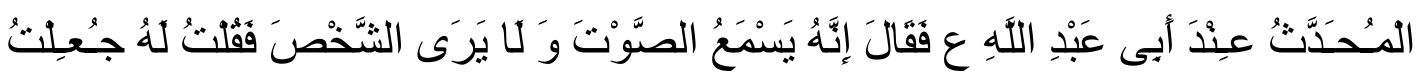

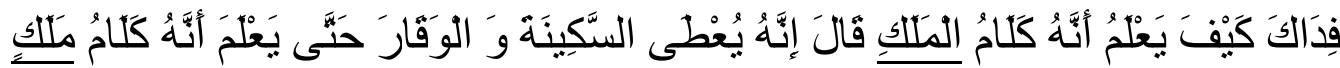

7- Dari Ali bin Ibrahim dari Muhammad bin Isa dari Yunus dari seorang lelaki dari Muhammad bin Muslim ia berkata : Seorang yang telah diceritakan berada pada Abi Abdullah ia mengatakan bahwasannya ia mendengar suara dan tidak melihat seseorang, aku berkata kepadanya : Benarkah? Bagaimana ia tahu bahwasannya itu adalah suara Malaikat? Ia menjawab : Itu adalah sesuatu yang sangat hening dan aku yakin itu adalah suara malaikat yang diucapkan. (Ushul Kafi 2, bab : Para Imam Diceritakan dan Difahamkan, hlm. 14, no. Riwayat. 4)

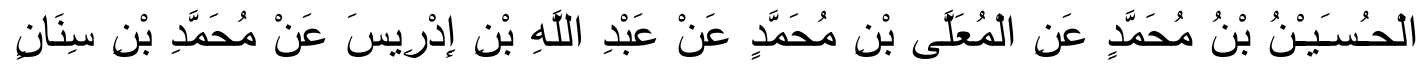

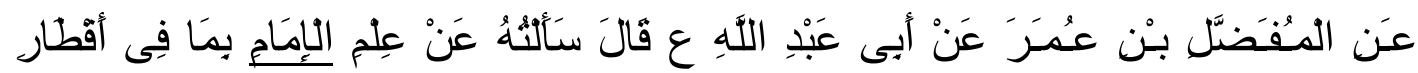

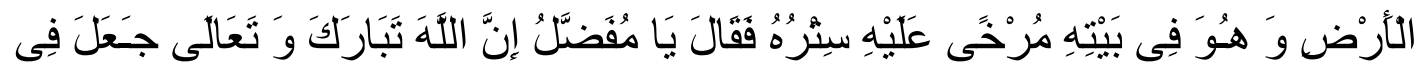

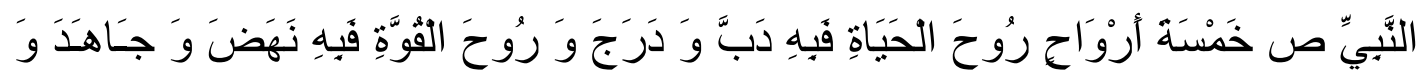

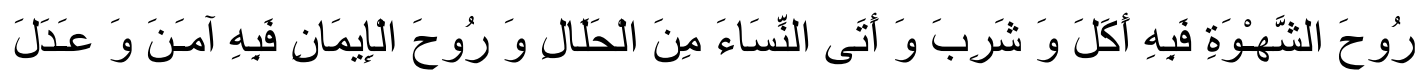

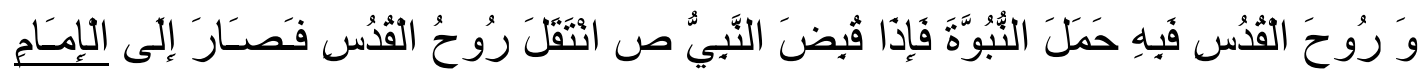




\section{Jurnal Asy-Syukriyyah}

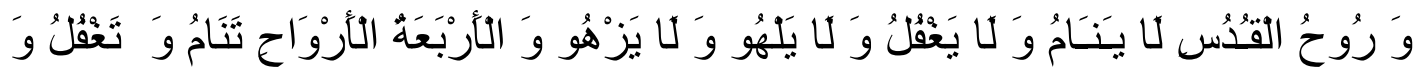

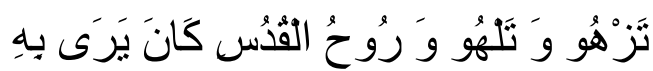

8- Dari husain bin Muhammad dari al-Mu'alli bin Muhammad dari Abdi Idris dari Muhammad bin Sinan dari Mufadhdhal Ibnullah bin Umar dari Abi Abdillah berkata : Aku menanyakannya tentang pengetahuan Imam akan perihal suatu negeri dan ia sedang berada di rumahnya dengan pintu yang tertutup rapat, kemudian berkata : Allah Swt menciptakan pada diri nabi Saw lima ruh, pertama : ruhul hayat, dengannya ia jalan dan bergerak, kedua : ruhul quwwah, dengannya ia berusaha dan bangkit, ketiga : ruhul syahwah dengannya ia makan dan minum, beriman, bersikap adil, menggauli istrinya, keempat : ruhul iman, kelima : ruhul qudus, dengannya ia menjalankan misi kenabiannya, jika ia wafat maka ruhul qudus tersebut berpindah kepada Imam. (Ushul Kafi 2, bab : Ruh-ruh yang masuk kepada para Imam, hlm. 17, no. Riwayat. 3)

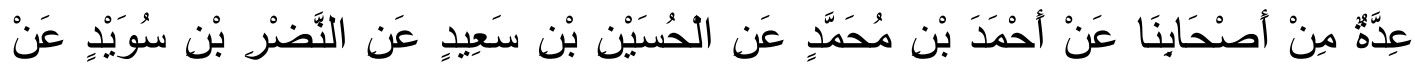

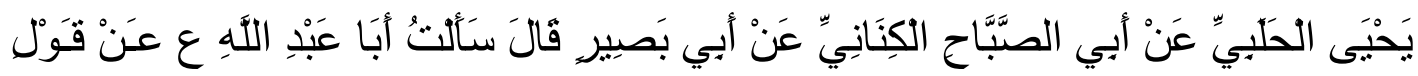

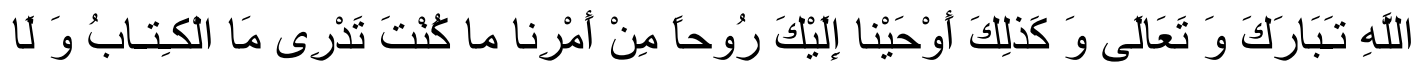

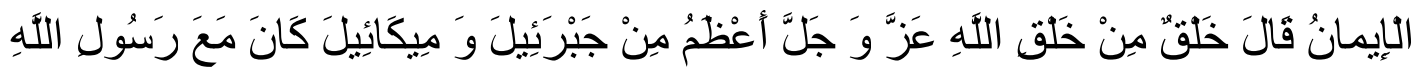

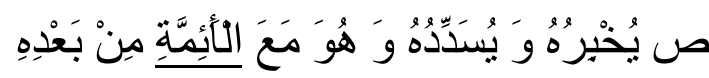

9- Dari sahabat-sahabat kami dari Ahmad bin Muhammad dari al-Husain bin Iddah Sa'id bin Nadhar bin Suwaid dari Yahya al-Halbi dari Abi Shabah al-Kinani dari Abi Bashir ia berkata: Aku bertanya kepada Abu Abdillah tentang firman Allah : Dan demikianlah Kami wahyukan kepadamu wahyu (al-Qur'an) dengan perintah Kami. Sebelumnya kamu tidaklah mengetahui apakah al-kitab (al-qur'an) dan tidak pula mengetahui apakah iman itu. Ia melanjutkan perkataannya : Itu adalah salah satu makhluk Allah lebih hebat dari Jibril dan Mikail, ia ada dalam diri Rasulullah Saw dan Para Imam setelah nabi Saw. (Ushul Kafi 2, bab : Ruh yang ditiupkan dalam diri Para Imam, hlm. 17, no. Riwayat. 1)

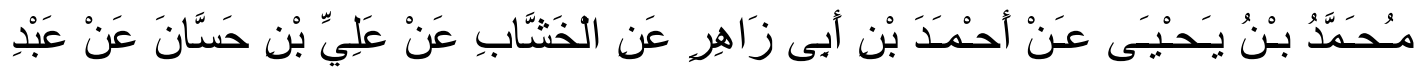

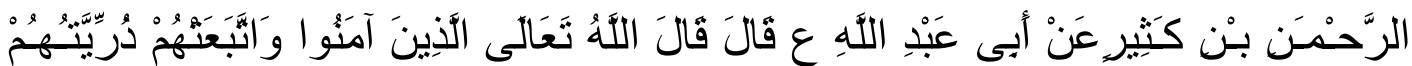

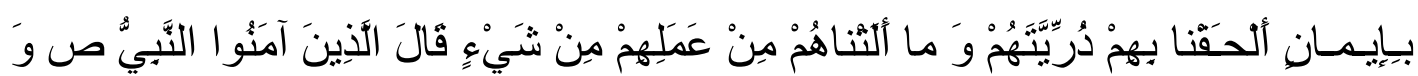




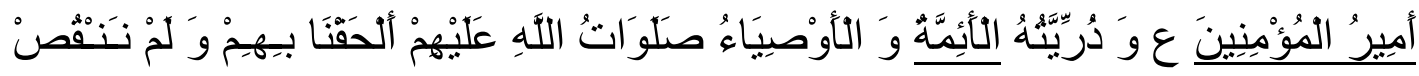

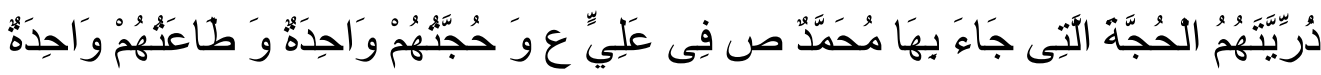

10- Dari Muhammad bin Yahya dari Ahmad bin Abi Zahir dari Abdurahman bin Katsir al-Khasysyab dari Ali bin Hassan dari Abi Abdillah berkata : Allah Swt berfirman : Dan orang-orang yang beriman, dan yang anak cucu mereka mengikuti mereka dalam keimanan, Kami hubungkan anak cucu mereka dengan mereka, dan Kami tiada mengurangi sedikitpun dari pahala amal mereka. Orang-orang beriman berkata : nabi dan Amirul Mu`minin keturunan mereka yaitu Para Imam dan Pewaris Nabi akan bertemu dan keturunan mereka tidak akan Kami kurangi dalam hal berhujah pada diri Ali, mematuhi mereka sama saja, begitu juga berhujjah dengannya. (Ushul Kafi 2, bab : Kesesuaian Keberanian, Pengetahuan dan Mentaaiti Para Imam sama, hlm. 21, no. Riwayat. 1)

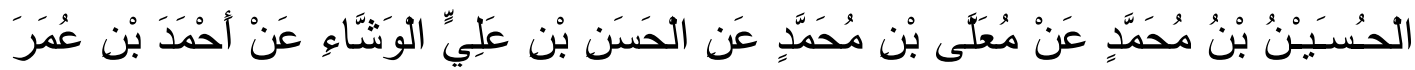

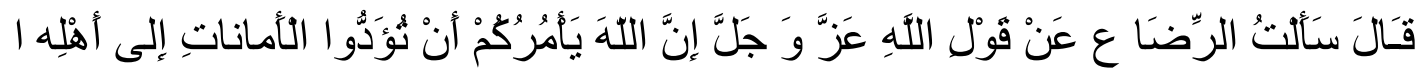

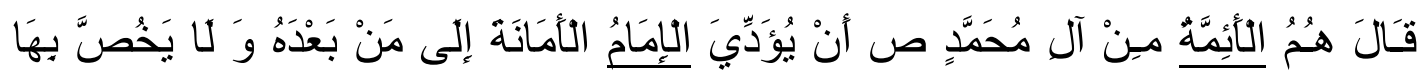

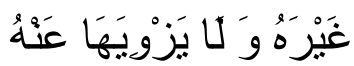

11- Dari al-Husain bin Muhammad dari Mu'alla bin Muhammad dari Hasan bin Ali alWasysya dari Ahmad bin Umar ia berkata : Aku bertanya kepada Ridha tentang firman Allah : Sesungguhnya Allah menyuruh kamu menyampaikan amanat kepada yang berhak menerimanya, mereka adalah Para Imam dari keturunan nabi Muhammad Saw, Imam harus menyerahkan kepada generasi penerusnya bukan orang lain dan tidak mengucilkan dari nya. (Ushul Kafi 2, bab : Seorang Imam mengetahui Penggantinya dan firman Allah : Sesungguhnya Allah menyuruh kamu menyampaikan amanat kepada yang berhak menerimanya turun pada mereka, hlm. 23, no. Riwayat. 2) 


\section{Jurnal Asy-Syukriyyah}

\section{Literatur Sunni}

Adapun dalam tradisi Sunni, banyak sekali kita temukan tafsir-tafsir yang membahas tentang terminologi Khalifah/Imam. Untuk membatasi, penulis hanya memilih satu Tafsir saja sebagai perbandingan dengan Tafsir Syi'ah.

\section{Tafsir Bahrul Muhith (Abu Hayyan):}

وقرأ الجمهور : خليفة، بالفاء، ويحتمل أن يكون بمعنى الخالف، ويحتملأن يكون بمعنى المخلوف، و إذا كان بمعنى الفاعل كان معناه: القائم مقام غيره في الأمر الذي جعل إلئه إليه.

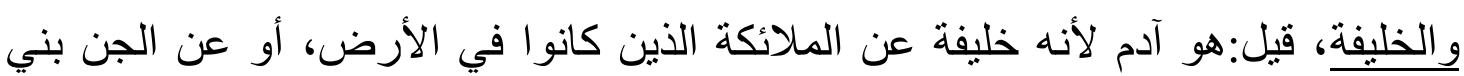
الجان، أو عن إبليس في ملك الأرض، أو عن الله تعالى، وهو فول الأله ابن مسعود و ابن عباس.

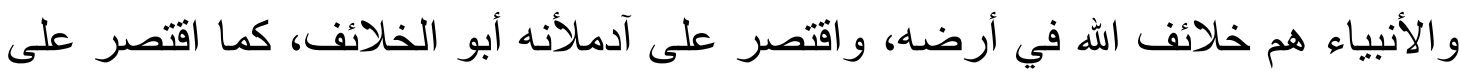

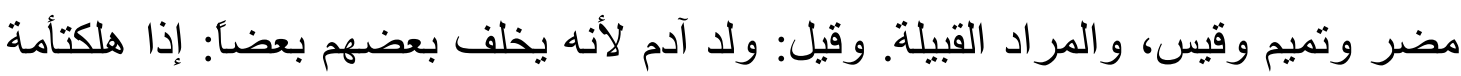

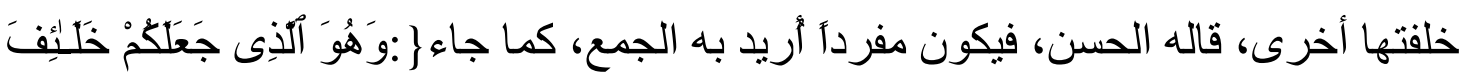

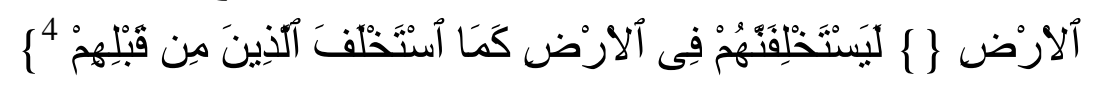

Khalifah mengandung makna wakil atau yang diwakilkan. Dan seorang Khalifah menurut Ibnu Mas'ud dan Ibnu Abbas adalah Nabi Adam AS. sebagai wakil Malaikat di muka bumi, atau wakil Jin dan para keturunannya, atau juga wakil Iblis dari kalangan malikat di bumi, atau wakil Tuhan (Allah SWT), sesungguhnya seluruh Nabi adalah Wakil Allah di bumi ini, namun hanya Nabi Adam AS. sajalah yang disebutkan dikarenakan Ia adalah Pendahulu para Wakil Allah SWT yang lainnya.

وقيل: الخليفة اسم لكل من انتقل إليه تدبير أهل الأرض و النظر في مصالحهم،كما أن كل من ولى الروم: قيصر، و الفرس: كسرى، و اليمن: تبع. وفي المستخلف فيه آدم قولان:

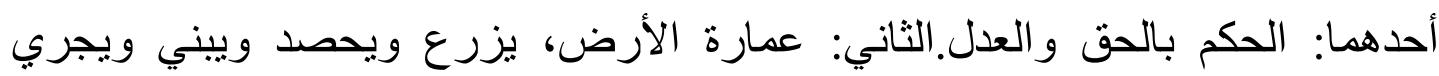
الأنهار.

Khalifah adalah suatu makhluk yang mengurusi segala permasalahan penghuni bumi untuk kemaslahatannya, seperti Raja Romawi (Kaisar), Raja Persia (Kisra), Raja Yaman (Taba'), atau Khalifah Bumi (Nabi Adam AS.), yaitu yang memenuhi 2 syarat :1.Berlaku adil,2.Berbuat untuk kemaslahatan dimuka bumi.

\footnotetext{
${ }^{4}$ Abu Hayyan, Tafsir Bahrul Muhith, Darul Kutub Ilmiyah Beirut, hal.283-284.
} 


\section{Penutup}

Setelah melihat terminologi khalifah dan imam dalam Tafsir al-Qummi dan Ushul al-Kafi, dapat disimpulkan bahwa dikalangan syi'ah pun istilah khalifah sudah dikenal sejak dahulu, hanya saja sosok yang diakui oleh kelompok syi'ah ini dikhususkan hanya untuk Ali bin Abi Thalib dan Ahli Baitnya. Sedangkan dikalangan sunni, penyematan gelar khalifah tidak dikhususkan pada personal seseorang khalifah, tetapi ditujukan kepada siapa saja yang mampu menerapkan prinsip-prinsip keadilan dan kemaslahatan. Ini yang kemudian dikembangkan Al-Mawardi -mewakili kelompok sunni-- dalam Ahkam Sulthaniyah-nya : Bahwasannya suatu Negara harus memiliki prinsip-prinsip dasar dalam pembentukannya, seperti: Teknis pemilihan kepala pemerintahan, system kebijakan keuangan, penegakan supremasi hukum, dll. ${ }^{5}$

Terminologi khalifah terus mengalami perkembangan makna yang luas, seperti yang dijelaskan Ali Abdu Raziq tentang sebab penamaan Khalifah, Hak dan kewajiban sebagai Khalifah, Legitimasi kekuasaan yang tidak terbatas hanya dari agama (Allah SWT), namun juga dari umat islam, dsb. ${ }^{6}$

\footnotetext{
${ }^{5}$ Abu Hasan Ali b.Muhamad b. Habib Al-Mawardi, Ahkam Sulthaniyah wa wilayat Diniyah. Maktabah Dar Ibnu Qutaibah -Kuwait.

${ }^{6}$ Ali Abdul Raziq, Al-Islam wa Ushul al-Hukm, Mathba'ah Misr-Cairo.1925 M.
} 


\section{Jurnal Asy-Syukriyyah}

\section{DAFTAR PUSTAKA}

Abu Hasan Ali Ibrahim Al-Qummi,

Tafsir Al-Qummi, Darul Kutub, Qumm-Iran,

Muhammad bin Ya'qub Al-Qulainiy,

Ushul Kafi, Darul Murtadha Beirut.

Abu Hayyan,

Tafsir Bahrul Muhith, Darul Kutub Ilmiyah Beirut

Abu Hasan Ali b.Muhamad b. Habib Al-Mawardi,

Ahkam Sulthaniyah wa wilayat Diniyah. Maktabah Dar Ibnu Qutaibah -Kuwait.

Ali Abdul Raziq,

Al-Islam wa Ushul al-Hukm, Mathba'ah Misr-Cairo.1925 M. 